\title{
Mucoadhesive polymer films for tissue retraction in laparoscopic surgery: Ex-vivo study on their mechanical properties
}

\author{
Zhigang Wang ${ }^{\text {a,* }}$, Lik-Ren Tai ${ }^{\mathrm{b}}$, Donald McLean ${ }^{\mathrm{a}}$, Emma J. Wright ${ }^{\mathrm{b}}$, Gordon J Florence ${ }^{\mathrm{b}}$, \\ Stuart I Brown ${ }^{\mathrm{a}}$, Pascal Andre ${ }^{\mathrm{c}}$ and Alfred Cuschieri ${ }^{\mathrm{a},{ }^{*}}$ \\ ${ }^{a}$ Institute of Medical Science and Technology (IMSaT), University of Dundee, Wilson House, \\ MediPark, Dundee DD2 1FD, UK \\ ${ }^{\mathrm{b}}$ School of Chemistry, University of St Andrews, North Haugh, St Andrews KY16 9ST, UK \\ ${ }^{\circ}$ School of Physics and Astronomy, University of St Andrews, St Andrews KY16 9SS, UK
}

\begin{abstract}
Safe and effective manipulation of soft tissue during laparoscopic procedures can be achieved by the use of mucoadhesive polymer films. A series of novel adhesive polymer films were formulated in house based on either Carbopol or Chitosan modified systems. The mechanical properties of the polymers and their adherence to bowel were evaluated using exvivo pig bowel immersed in $37{ }^{\circ} \mathrm{C}$ water bath and connected to an Instron tensiometer. Young's modulus was $300 \mathrm{kPa}$ for the Carbopol-polymer and $5 \mathrm{kPa}$ for the Chitosan-polymer. The Chitosan-polymer exhibited much larger shear adhesion than its tensile adhesion: $3.4 \mathrm{~N}$ vs. 1.2. Both tensile and shear adhesions contributed to the large retraction force $(2.6 \mathrm{~N})$ obtained during 1 polymer-bowel retraction testing. Work of adhesion at the polymer/serosa interface, defined as the area under the force curve, was $64 \mathrm{~mJ}$, which is appreciably larger than that reported with existing polymers. In conclusion, adhesive polymers can stick to the serosal side of the bowel with an adhesive force, which is sufficient to lift the bowel, providing a lower retraction stress than that caused by laparoscopic grasping which induces high localized pressures on the tissue.
\end{abstract}

Keywords: mucoadhesive polymer, mechanical property, adhesive force, laparoscopic surgery, bowel retraction

\section{Introduction}

Mucoadhesive polymers (MAP) hydrate on contact with moist tissues and adhere to the target tissue [1]. MAP is widely used in controlled drug delivery [2-3]. The interfacial forces between mucin surface glycoproteins and the polymers depend on several mechanisms such as hydrogen bonding, Van der Waals interactions, hydrophobic effects (lipid penetration), ionic bonding, and polymer chemical functionality and macromolecular structure. MAPs have also been used as mucoadhesive films in minimal access surgery (MAS) such as for locomotion of endo-robots as this requires adhesion. Another report has shown that muco-adhesive polymers can generate high static friction which is influenced by the film geometry [4]. Our on-going research interest is concerned with exploitation of the adhesiveness of the polymer films for tissue manipulation including retraction during laparoscopic surgery. In

\footnotetext{
${ }^{*}$ Corresponding author. E-mail: z.z.wang@dundee.ac.uk.

*Corresponding author. E-mail: a.cuschieri@dundee.ac.uk.
} 
addition to improved adhesiveness of the MAPs, our on-going research includes development of a novel class of ferromagnetic MAPs. Previously, we reported a tissue surface magnetization method by applying a small volume of glue -based magnetic media to the mucosal surface [5], which enabled retraction of the target tissue by a magnet probe. In this system, , the major limitation was the low bond strength between the glue and the wet tissue, such that the pellet formed by the polymerized glue tended to peel off the retracted tissue with continued lift by the magnetic probe. An important study [6] reported that the average force required for bowel retraction force was $2.5 \mathrm{~N}$. This paper describes the development and characterisations of adhesive polymers able to adhere strongly on serosal side of the bowel wall, achieving an adhesion force $>2.5 \mathrm{~N}$, to enable bowel retraction and manipulation.

\section{Materials and methods}

\subsection{Mucoadhesive polymer films}

A series of adhesive mono- and bi-layer polymer films were formulated in house, in which the adhesive layer was based on either thiobutylamidine (TBA)-chitosan (mol wt $=375 \mathrm{kD}$, loading of TBA $=150 \mu \mathrm{mol} / \mathrm{g}$ ) or Carbopol 971. Each polymer sample was cast in $60 \mathrm{~mm}$ diameter Teflon moulds and air dried at $50{ }^{\circ} \mathrm{C}$. Detailed materials and film processing methods are described below.

\subsubsection{Chitosan-based adhesive polymers}

Chitosan (high molecular weight range: $>375 \mathrm{kD}, 2944 \mathrm{mg}, 18.17 \mathrm{mmol}$ ) was dissolved under stirring in $\mathrm{H}_{2} \mathrm{O}-\mathrm{AcOH}(99: 1,300 \mathrm{~mL})$ for $1 \mathrm{~h}$ before the addition of 2-iminothiolane hydrochloride (1000 $\mathrm{mg}, 7.27 \mathrm{mmol})$. The mixture was left to stir for $24 \mathrm{~h}$. Dithiothreitol $(1122 \mathrm{mg}, 7.27 \mathrm{mmol})$ was then added to the mixture and further stirred for $1 \mathrm{~h}$. All the steps were completed at room temperature.

Chitosan-conjugate $(600 \mathrm{mg})$, poloxamer $(200 \mathrm{mg})$, propylene glycol $(200 \mathrm{mg})$ and acetic acid $(0.1$ $\mathrm{mL}$ ) was added into deionised $\mathrm{H}_{2} \mathrm{O}(80 \mathrm{~mL})$. The resulting mixture (Fig.1a) was stirred by an overhead mechanical stirrer at $200 \mathrm{rpm}$ for $3 \mathrm{~h}$. The clear viscous gel solution was transferred into a PTFE circular mould (diameter: $78 \mathrm{~mm}$; height: $30 \mathrm{~mm}$ ) and dried inside a fume hood at room temperature for 4 days or at $30{ }^{\circ} \mathrm{C}$ for 3 days. Localized hydration was performed with deionised $\mathrm{H}_{2} \mathrm{O}$ in event of uneven drying. The drying was stopped to prevent a complete dried-out as soon as the material materialised and can be handled as a film. The resulting soft sticky material was transferred for storage at $4{ }^{\circ} \mathrm{C}$ to retain moisture required for adhesiveness.

\subsubsection{Carbopol polymer blend}

A mixture of Carbopol $971(450 \mathrm{mg})$, poloxamer $(450 \mathrm{mg})$, hydroxypropyl methylcellulose (300 $\mathrm{mg})$, polyvinyl pyrrolidone $(150 \mathrm{mg})$ and propylene glycol $(150 \mathrm{mg})$ were firstly added into deionised $\mathrm{H}_{2} \mathrm{O}(90 \mathrm{~mL})$, followed by the subsequent addition of triethanol amine $(0.3 \mathrm{~mL})$. The mixture (Fig. $\left.1 \mathrm{~b}\right)$ was stirred at room temperature by an overhead mechanical stirrer at $300 \mathrm{rpm}$ for $18 \mathrm{~h}$. The resulting viscous gel was then centrifuged at 6000 to $8000 \mathrm{rpm}$ for $15 \mathrm{~min}$ to remove trapped air bubbles. 


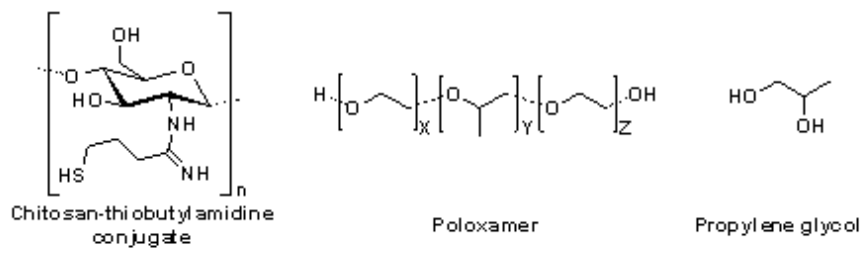

(a)

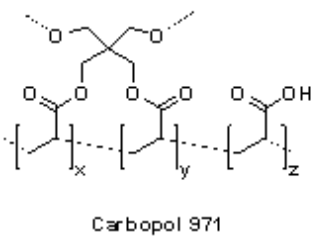

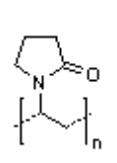

Polyvinyl

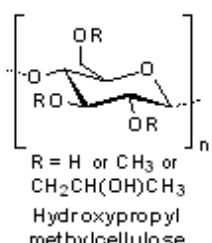

methylcellulose

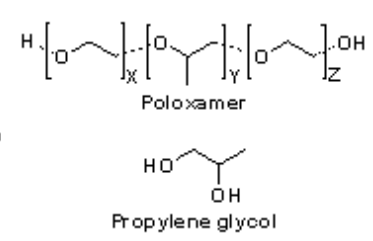

(b)

Fig. 1. Mucoadhesive polymer formulation: (a) Chemical species employed in the preparation of chitosan-based adhesive polymers; (b) Chemical species employed in the preparation of carbopol-based adhesive polymers.

The clear viscous gel was transferred into a PTFE circular mould (diameter: $78 \mathrm{~mm}$; height: $30 \mathrm{~mm}$ ) and dried inside a fume hood at room temperature for 4 - 5 days. Alternative drying method can be carried out in an incubator at $30{ }^{\circ} \mathrm{C}$ for $5-6$ days. The film was completely dried for the ease of removal from PTFE mould and for storage.

\subsection{Mechanical properties of mucoadhesive polymer film}

The mechanical properties of mucoadhesive films were evaluated using the Instron 5564 tensiometer (Intron Ltd, Buckinghamshire, UK), as described by Mura et al [7]. Briefly, a strip of MAP film $(20 \mathrm{~mm} \times 10 \mathrm{~mm})$ cut by a metal punch was used for testing. The sample which had to be free from air bubbles or physical imperfections was fixed at both ends by medical grade cyanoacrylate adhesive (Loctite 4014, Henkel, and Dusseldorf, Germany) between two stainless steel plates. The bottom plate was held in place by being clamped in a heavy vice and the top plate was connected to the load cell (the crosshead) of the Instron tensiometer via a keyless drill chuck to facilitate exchange of probes. The initial distance between the two plates was set to be $16 \mathrm{~mm}$, and the load cell was balanced to ensure the force measured resulted only from material strain (tension). During measurement, the film was pulled by top plate at a rate of $5 \mathrm{~mm} / \mathrm{min}$ to a distance when the film broke off, with force and elongation data recorded and tensile strength (stress at break) and elongation at break calculated. The force and elongation curve was then converted into corresponding strain and stress curve, and film's Young modulus was derived from the slope at its linear region [8]. Each polymer sample was tested 6 times and a new specimen was used for each test.

\subsection{Mucoadhesive film adhesion test using ex-vivo porcine bowel}

Tensile and shear forces were measured for assessment of the extent of the adherence of polymer films to ex-vivo porcine bowel, as illustrated in Fig. 2(a), again using the Instron 5564 tensiometer. Each polymer sample was tested 6 times and a new bowel specimen was used for each test. 


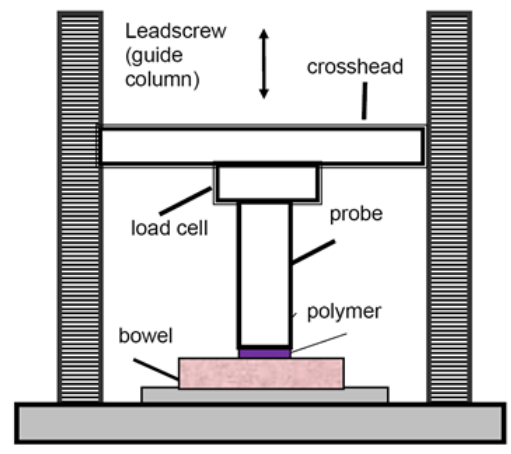

(a)

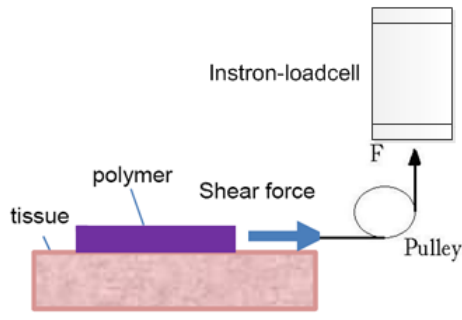

(b)

Fig. 2 Schematic illustrations (not drawn to scales) of mucoadhesive polymer-tissue adhesion test based on Instron tensiometer: (a) Polymer adhesive tensile strength test; (b) Polymer adhesive shear strength test.

In tensile test, we used a stainless steel plate with end surface area of $15 \mathrm{~mm} \times 15 \mathrm{~mm}$. For thin polymer films (carbopol-based), the test specimen was mechanically fixed onto the plate by clamping its (folded) edges (with specimen test area $15 \mathrm{~mm} \times 15 \mathrm{~mm}$, i.e., identical to the plate end surface area). This mechanical fixation of polymer film sample was preferred to using cyanoacrylate adhesive as this might change local chemistry of the film, especially when very thin. For the thick Chitosan polymer films, the mechanical fixation was not possible because of breakage of the edges. For these films cyanoacrylate adhesive (Loctite 4014) was used to fix Chitosan sample to the plate, a method previously reported by others [9].

The probe was then connected to the crosshead of the Instron tensiometer, and the attached polymer sample was brought into contact with the bowel $(30 \times 30 \mathrm{~mm})$ for adhesion tests at selected contact time with a constant preload. For this study, the bowel lumen was opened longitudinally, cut into $30 \times 30 \mathrm{~mm}$ sample and glued on a plastic plate $(50 \times 50 \mathrm{~mm})$ with serosal side upwards. The sample holding plastic plate was secured on a platform within a water bath at a temperature of $37^{\circ} \mathrm{C}$.

In these ex-vivo polymer tensile adhesion studies based on the Instron tensiometer, we adapted a method, previously described by Mura et al [7], in which the probe (polymer) is lowered at a speed of $1 \mathrm{~mm} / \mathrm{min}$ to contact the tissue at a force of $1 \mathrm{~N}$ for a contact time of $1 \mathrm{~min}$. It is then withdrawn at a rate of $1 \mathrm{~mm} / \mathrm{min}$ until the film detaches completely from the tissue. The recorded force and extension data can be processed. Several parameters can be used to describe mucoadhesive performance of the sample: the detachment force $F(\mathrm{~N})$ or peak force which measures the resistance to the withdrawal of the probe, and the area under the force/extension curve (AUC) which represents the work $W(\mathrm{~J})$ required for detachment of the two systems (tissue/polymeric film) [9]. Work $W$ was calculated with a Matlab (MathWorks, UK) based program relying on linear trapezoidal rule [10]:

$$
W=\sum_{i=0}^{N-1}\left(x_{i+1}-x_{i}\right) *\left(F_{i}+F_{i+1}\right) / 2
$$

where $W$ is adhesion work, $x$ is elongation distance, $F$ is force, $i$ is data sampling point and $N$ is total number of data point. To facilitating comparison between different sized probes, a parameter $E$ (unit: $\mathrm{Jm}^{-2}$ ) was derived from dividing the work by the probe area. This parameter is equivalent to surface (or adhesion) energy, which has been used for studying surgical glue adhesion studies $[11,12]$. The stress $[\sigma(\mathrm{Pa})]$ at peak force was also derived from dividing $F$ by the probe-polymeric film area. 
In the shear test, a MAP film attached to the clamp was placed onto the bowel tissue with $100 \mathrm{~g}$ mass (weight) loaded for a contact time of $1 \mathrm{~min}$. The applied load was selected [4] such that the pressure on the bowel surface was within the range of values of the intra-abdominal pressure on the colon of the human body. The clamp (plate) was connected via a thread and a pulley of negligible friction to the load cell of the Instron tensiometer [7], as illustrated in Fig. 2(b). The tensile testing machine pulled the clamp forward at constant speed $(1 \mathrm{~mm} / \mathrm{min})$ and recorded the trace of the generated friction (shear) force. Pulling the clamp without the $100 \mathrm{~g}$ load was also conducted for comparison.

\section{Results and discussion}

\subsection{Polymer film mechanical properties}

Prior to any testing, re-hydration of the dried carbopol-based polymer was achieved by submersion of the film into phosphate buffer solution (PBS) or deionised $\mathrm{H}_{2} \mathrm{O}$ for $3 \mathrm{sec}$. The film was left to stand for $3 \mathrm{~min}$ to allow complete moisture absorption. The chitosan-based mucoadhesive films were required to induce with moisture after a period of time under storage in order to retain its adhesiveness. Phosphate buffer solution (PBS) was applied evenly in drops onto the film surfaces. The film was left to stand for 10 min to allow complete absorption.

Polymer samples used in this experiment were selected to have identical thickness, with thickness of carbopol-based film being $0.5 \mathrm{~mm}$, compared to the $1.5 \mathrm{~mm}$ thickness of chitosan-based films. Test raw data of load and extension were recorded by the Instron PC, and were further analyzed using Matlab and Excel with results shown in Table 1. The tensile strength and Young's modulus of the Carbopol-films were in the range of mucoadhesive polymers reported by Mura [7] which are lower but in same scale as the modulus of bowel tissue. Film thickness variation and degree of moisture have mainly contributed to variation of the results, and improvement in standardization of test film specimen' size, thickness and rehydration condition has been ongoing but these results will be reported elsewhere. It is obvious that Chitosan-based film has very low tensile strength (like a gel) and obviously such films would not provide sufficient force for tissue manipulation and retraction.

Table 1

Mechanical properties of mucoadhesive film samples (Mean $\pm \mathrm{SD}, \mathrm{n}=6$ ) at room temperature $\left(22^{\circ} \mathrm{C}\right)$

\begin{tabular}{|l|c|c|c|}
\hline Polymer type & $\begin{array}{c}\text { Tensile strength } \\
(\mathrm{kPa})\end{array}$ & $\begin{array}{c}\text { Elongation at break } \\
(\%)\end{array}$ & $\begin{array}{c}\text { Young's modulus } \\
(\mathrm{kPa})\end{array}$ \\
\hline Carbopol-based film & $252 \pm 106$ & $97 \pm 40$ & $296 \pm 149$ \\
\hline Chitosan-based film & $10 \pm 7$ & $190 \pm 39$ & $4.5 \pm 2.1$ \\
\hline
\end{tabular}

\subsection{Polymer-tissue adhesion}

For study of in-situ adhesion, polymer films were cut into $15 \mathrm{~mm} \times 15 \mathrm{~mm}$ specimens, then placed and adhered to the serosal side of an ex-vivo bowel segment at $37^{\circ} \mathrm{C}$. Polymeric film tensile and shear adhesions were measured separately using the Instron tensiometer system as described previously in section 2.3. Shear adhesion in peak force and work were much greater than those in tensile adhesion 
(Table 2). Chitosan-based films exhibited very weak adhesion (Table 2), mainly due to their weak intrinsic mechanical properties as shown in Table 1.

Table 2

Polymer specimen $(15 \mathrm{~mm} \times 15 \mathrm{~mm})$ adhesion to the tissue at $37^{\circ} \mathrm{C}(\mathrm{Mean} \pm \mathrm{SD}, \mathrm{n}=6)$

\begin{tabular}{|l|c|c|c|c|}
\hline Polymer films & $\begin{array}{c}\text { Tensile } \\
\text { adhesion }(N)\end{array}$ & $\begin{array}{c}\text { Shear } \\
\text { adhesion }(N)\end{array}$ & $\begin{array}{c}\text { Tensile work } \\
(\mathrm{mJ})\end{array}$ & $\begin{array}{c}\text { Shear work } \\
(\mathrm{mJ})\end{array}$ \\
\hline Carbopol-based & $1.2 \pm 0.3$ & $3.4 \pm 0.6$ & $8.1 \pm 3.7$ & $38.2 \pm 12.7$ \\
\hline Chitosan-based & $0.4 \pm 0.1$ & $0.8 \pm 0.3$ & $2.1 \pm 0.8$ & $6.7 \pm 2.2$ \\
\hline
\end{tabular}

\subsection{Tissue retraction using mucoadhesive polymer film}

The retraction force of MAP films was tested using ex-vivo porcine bowel. Ex-vivo porcine bowel was fixed onto a test platform placed in a water bath at a temperature of $37{ }^{\circ} \mathrm{C}$. Carbopol or chitosan based-polymer films (60 $\mathrm{mm}$ diameter specimen) were placed onto moist serosal side of bowel with a pre-load of $1 \mathrm{~N}$ for $1 \mathrm{~min}$. An aluminium probe of $25 \mathrm{~mm}$ diameter was connected to the Instron loadcell and brought into contact with the polymer and fixed with a drop of medical grade cyanoacrylate adhesive(Loctite 4014) to the probe end surface for bowel retraction through film-tissue adhesive force and measured adhesive parameters shown in Table 3. Since the retraction probe hah smaller diameter than the polymer sample, both tensile (right under the probe end surface) and shear adhesion contributed to the retraction with force and extension recorded by the Instron-based system.

Table 3

Practical polymer-bowel retraction with calculated parameters at $37^{\circ} \mathrm{C}$ (Mean $\pm \mathrm{SD}, \mathrm{n}=6$ ). $F$ is adhesion force, $W$ is adhesion work, $\sigma$ is adhesion stress, $E$ is adhesion energy, respectively.

\begin{tabular}{|c|c|c|c|c|}
\hline Polymers & $F(\mathrm{~N})$ & $W(\mathrm{~mJ})$ & $\sigma(\mathrm{kPa})$ & $E\left(\mathrm{Jm}^{-2}\right)$ \\
\hline Carbopol-based & $2.6 \pm 0.4$ & $64.1 \pm 19.2$ & $6 \pm 1.3$ & $22.8 \pm 6.8$ \\
\hline Chitosan-based & $1.7 \pm 0.3$ & $53.1 \pm 17.5$ & $5.3 \pm 0.9$ & $19.2 \pm 10.1$ \\
\hline
\end{tabular}

Carbopol-based polymer adhesive force during bowel retraction ranged from 2 to $3 \mathrm{~N}$ with an average of $2.6 \mathrm{~N}$ (Table 3). Work of adhesion at the polymer/serosa interface (area under the force curve), was $64 \mathrm{~mJ}$, which is appreciably larger than that reported with existing polymers with pure tensile retraction by Eouani et al [9] (1 $\mathrm{mJ}$ using $28 \mathrm{~mm}$ diameter probe). However, chitosan-based polymer performed much less favourably having adhesive force of $1.7 \mathrm{~N}$ and work of $53.1 \mathrm{~mJ}$. It was also observed that the work was not totally used for tissue retraction since a large portion of extension was due to plastic deformation of the polymer itself since the film started to break before loss of adhesion with bowel.

Reported studies by other groups [6] have shown that the average pull force that surgeons use to provide sufficient tension to the bowel was $2.5 \mathrm{~N}$ and the maximal force was just below $5 \mathrm{~N}$. The results in Table 3 indicate that carbopol-based Maps could provide sufficient tissue adhesion for retraction and bowel manipulation. Chitosan-based polymer would need further development for strengthening its mechanical properties for bowel use in bowel retraction, but in its present state has other applications. 
Another advantage of using MAPs for tissue retraction is the reduced stress (or pressure) when pulled at high tension due to their flexible and large contact surface area with the target tissue. For conventional laparoscopic graspers, average pressures at the graspers' tip vary from 210 to $650 \mathrm{kPa}$ [13]. Maximal stress generated from this ex-vivo bowel retraction at the probe and polymer interface was significantly lower, below $10 \mathrm{kPa}$ (Table 3), although it would be expected to increase when the probe diameter is reduced to $3-5 \mathrm{~mm}$ for laparoscopic surgery.

\section{Conclusion}

MAPs can stick to the serosal side of the bowel with an adhesive force, which is sufficient to lift and retract bowel. By using shearing of the polymer-tissue bonding interface, a further reduction in device dimension is possible for laparoscopic procedures. Retraction by MAPS is safer than conventional grasping because of reduced retraction stress to the target tissue.

\section{Acknowledgements}

This work was financially supported by the Engineering and Physical Sciences Research Council (EPSRC), UK, under Grant EP/H010033/1 and the Royal Society (GJF).

\section{References}

[1] Grabovac V, Guggi D, Bernkop-Schnurch A. Comparison of the mucoadhesive properties of various polymers. Adv Drug Deliv Rev. 2005;57(11):1713-23.

[2] Salamat-Miller N, Chittchang M, Johnston TP. The use of mucoadhesive polymers in buccal drug delivery. Advanced Drug Delivery Reviews. 2005;57(11):1666-91.

[3] Andrews GP, Laverty TP, Jones DS. Mucoadhesive polymeric platforms for controlled drug delivery. Eur J Pharm Biopharm. 2009;71(3):505-18.

[4] Dodou D, Breedveld P, Wieringa PA. The role of geometry in the friction generated on the colonic surface by mucoadhesive films. Journal of Applied Physics. 2006;100(1):014904-13.

[5] Wang Z, Wang L, Tang B, Frank T, Brown S, Cuschieri A. Retraction by surface ferromagnetisation of target tissues: preliminary studies on feasibility of magnetic retraction for endoscopic surgery. Surg Endosc. 2008;22(8):1838-44.

[6] Heijnsdijk EA, de Visser H, Dankelman J, Gouma DJ. Slip and damage properties of jaws of laparoscopic graspers. Surg Endosc. 2004;18(6):974-9.

[7] Mura P, Corti G, Cirri M, Maestrelli F, Mennini N, Bragagni M. Development of mucoadhesive films for buccal administration of flufenamic acid: Effect of cyclodextrin complexation. Journal of Pharmaceutical Sciences. 2010;99(7):3019-29.

[8] Shojaei AH, Paulson J, Honary S. Evaluation of poly(acrylic acid-co-ethylhexyl acrylate) films for mucoadhesive transbuccal drug delivery: factors affecting the force of mucoadhesion. Journal of Controlled Release. 2000;67(23):223-32.

[9] Eouani C, Piccerelle P, Prinderre P, Bourret E, Joachim J. In-vitro comparative study of buccal mucoadhesive performance of different polymeric films. European Journal of Pharmaceutics and Biopharmaceutics. 2001;52(1):45-55

[10] Gibaldi M, Perrier M, editors. Pharmacokinetics. 2nd ed. New York: Marcel Dekker; 1982

[11] Perrin BRM, Dupeux M, Tozzi P, Delay D, Gersbach P, von Segesser LK. Surgical glues: are they really adhesive? European Journal of Cardio-Thoracic Surgery. 2009;36(6):967-72.

[12] Iqbal J, Shahnaz G, Perera G, Hintzen F, Sarti F, Bernkop-Schnurch A. Thiolated chitosan: Development and in vivo evaluation of an oral delivery system for leuprolide. European Journal of Pharmaceutics and Biopharmaceutics. 2012;80(1):95-102.

[13] Cartmill JA, Shakeshaft AJ, Walsh WR, Martin CJ. High pressures are generated at the tip of laparoscopic graspers. Aust Nz J Surg. 1999;69(2):127-30.1. 